\title{
Vultures and honeybees
}

\section{Peter Bridgeford \& Holger Kolberg}

Vultures Namibia, P.O. Box 3699, Walvis Bay, Namibia

pmbridge@iway.na; holgerk@mweb.com.na

In October 2011, while ringing Lappetfaced Vulture Torgos tracheliotos chicks in the Ganab area of the Namib-Naukluft Park, Namibia, we came across an unusual occurrence: When we reached the chick in the nest, we found honeybees Apis mellifera, crowded over and covering the eyes of the young vulture.

The Namib-Naukluft Park (NNP), $49,785 \mathrm{~km}^{2}$, is the largest conservation area in Namibia managed by the Ministry Environment and Tourism. Established during the German colonial period and expanded over the years, this huge desert park is the main breeding area for Lappetfaced Vultures in the Namib Desert.
Although White-backed Vultures Gyps africanus occur sporadically in the Park, they do not breed here. In 1969, Sauer (1973) recorded up to 25 Cape Griffons Gyps coprotheres from the now extinct colony at Rostock, feeding with Lappetfaced Vultures in this area. With only about 20 of these griffons left in Namibia, they are seldom seen in the NNP today.

The Central Namib, with huge plains, acacia trees in dry watercourses and scattered inselbergs, dominates the northern region of the NNP where the main breeding area lies, between the Swakop and Kuiseb Rivers. Some of the larger ephemeral rivers further south, with riverine vegetation, mostly acacia 
trees, provide suitable nesting and

roosting sites. For a more comprehensive

report on the main breeding areas in the

NNP, see Bridgeford (2003). In the NNP,

the birds feed mainly on the gemsbok

Oryx gazella, springbok Antidorcas

marsupialis, Hartmann's mountain zebra

Equus zebra hartmannae and Ostrich

Struthio camelus. The vultures also feed

on domestic stock on neighbouring

commercial farms.

The ringing of over 800 Lappet-
1991 but this is the first time in 20 years

that we found honeybees around the

eyes of the vulture chicks. In the first

nest, the bees covered the pupil of the

one eye and the other eye was swollen

shut. Despite the handling of the chick

while ringing, the bees were not

aggressive. We smeared some mosquito

repellent on the bare skin of the head of

the chick and that appeared to keep the

bees away, but it was only a temporary

solution.

faced Vulture chicks in the NNP started in

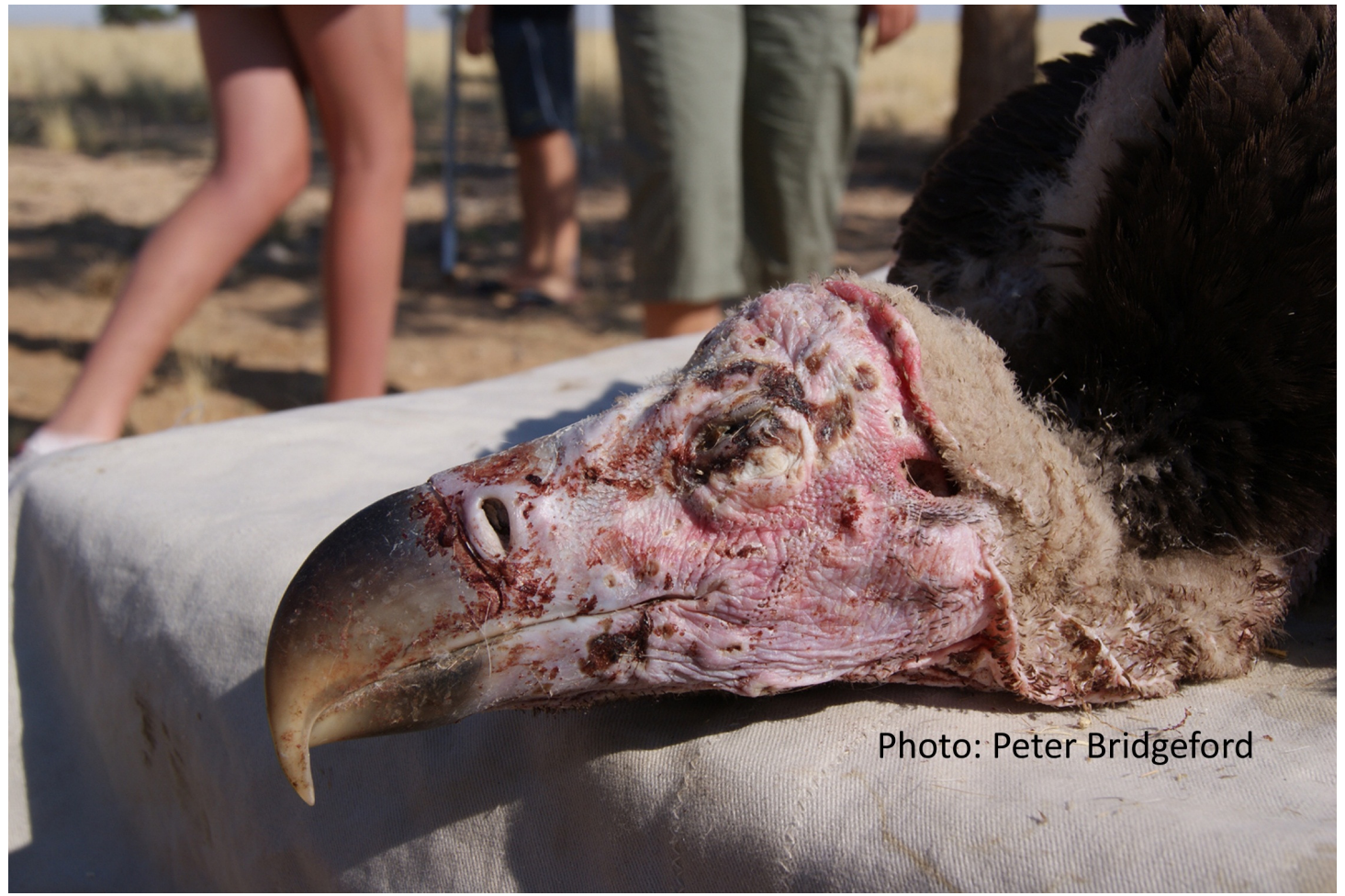

Figure 1. Necrotic ulcers on the bare skin of a young Lappet-faced Vulture's face. 
That evening, HK, leading the second ringing team, reported finding a chick on the ground under the nest with both eyes closed and it seemed to be blind. It was put back in the nest, but two days later, it was found dead on the ground under the nest.

During the next day's ringing, we found another chick in its nest, with necrotic ulcers on the bare skin of the head. Both eyes were gummed shut and the chick was in a poor condition and not responsive. Two hours later, the chick was on the ground under the nest, with both eyes closed. There were honeybees flying around the head of the bird. We cleaned the eyes with bottled water and cotton wool and rubbed 'betadine' antiseptic ointment on the skin around the eyes as it kept the bees away. We dribbled water into its beak. It drank readily and appeared to be thirsty and hungry. We then fed it a small piece of meat we had with us. We replaced the chick in the nest. The next day one eye was partly open and it was still in the nest.

Another, larger chick had dry scabs on the bare facial skin. It had its head under its wing when we reached the nest. Many bees were flying around the nest and the chick. This was the second chick seen with its head under the wing to escape the bees. 


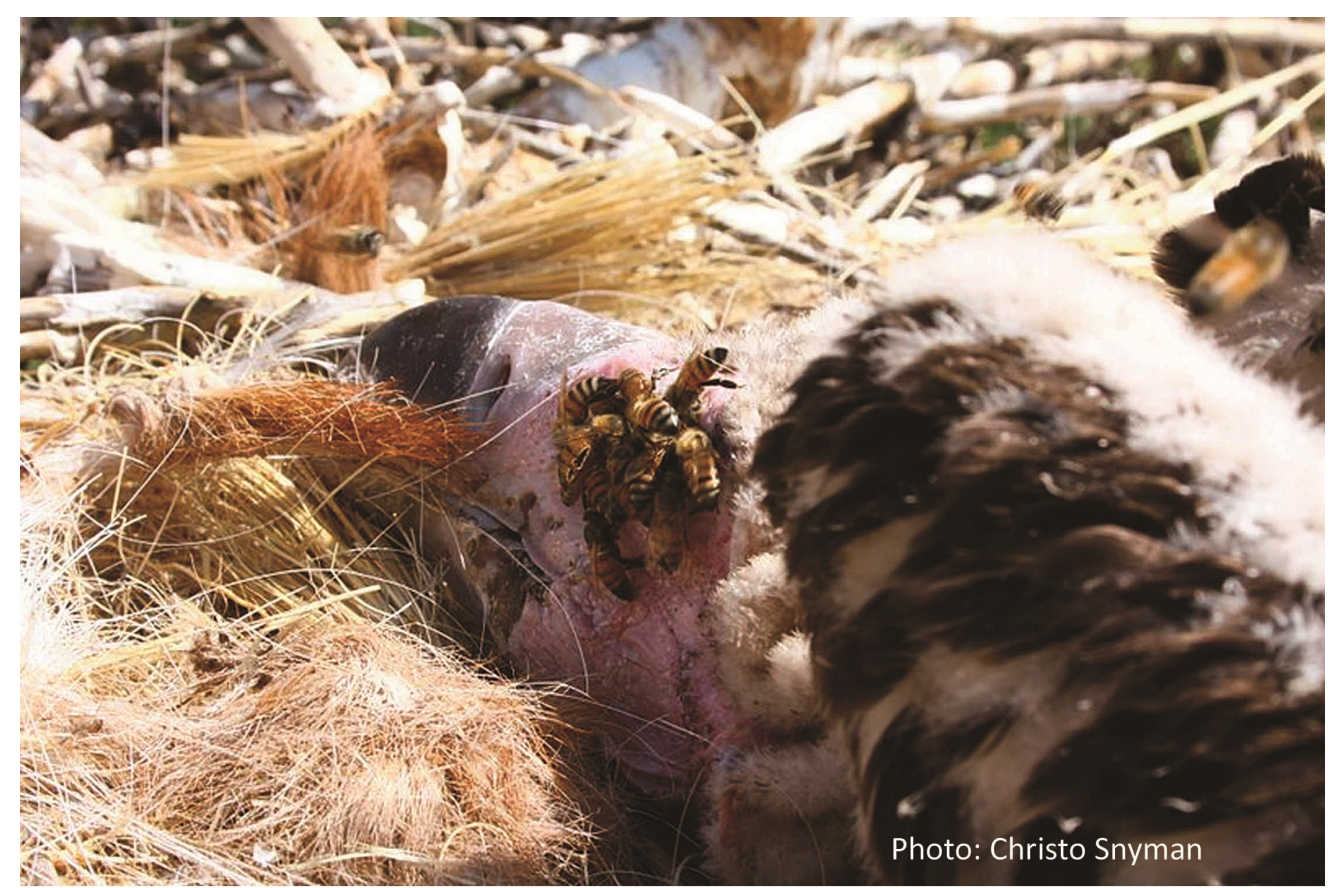

Figure 2. At least ten bees covered the eyes of the young bird.

The bees appeared to be after moisture and found this on the eye and mouth of the vulture chicks. Small chicks could not escape the tormenting bees, but larger chicks hid their head under a wing. We found the bees attracted to water bottles and dripping water from water tanks on the vehicles. Soft-drink cans attracted many bees.
During the past three years, Namibia had above average rainfall over most of the country, including the Namib. Bees and other invertebrates increased in numbers, but in 2011, the area between the Kuiseb and Swakop Rivers only had scattered showers. As a result, the bees were desperate for moisture and the vulture chicks could not escape. 


\section{REFERENCES}

Bridgeford, P. \& M. 2003. Ten years of monitoring breeding Lappet-faced Vultures Torgos tracheliotos in the Namib-Naukluft Park, Namibia. Vulture News, Vulture Study Group, Johannesburg.

Sauer, E.G.F. 1973. Notes on the behavior of lappet-faced vultures and Cape vultures in the Namib Desert of South West Africa. Madoqua Ser. II, Vol. 2: 43-62. 